\title{
Microstructural Morphology Changes of the Lead-Tin Eutectic Alloy by Different Undercooling Levels
}

\author{
Heesam Kang* and Wooyoung Yoon \\ Division of Materials Science and Engineering, Korea University, 1, 5Ga, Anam-dong, Sungbuk-ku, Seoul 136-701, Korea
}

Experimental work is described in undercoolings and microstructures of $\mathrm{Pb}$-Sn eutectic alloy droplets emulsified in oil bath. By controlling experimental variables, the final droplet size produced was in the range of 10 to $300 \mu \mathrm{m}$, and measured undercoolings ranged up to about $70 \mathrm{~K}$. Microstructures of the droplets depend strongly on the degree of undercooling before solidification. By increasing undercooling, three major microstructure transitions, which include the morphological changes of eutectic phase from lamellar to anomalous in lower undercooling level and of primary $\alpha-\mathrm{Pb}$ phase from dendrite to equiaxed grains in higher undercooling levels, are observed. The phase change from eutectic to primary $\alpha-\mathrm{Pb}$ dendrite plus eutectic is also observed. The physical mechanism of these microstructure transitions is analyzed on the basis of the Lipton-Kurz-Trivedi theory for dendrite growth and the Jackson-Hunt theory for lamellar eutectic growth.

(Received February 16, 2004; Accepted August 2, 2004)

Keywords: lead-tin eutectic alloy, droplet emulsion technique, anomalous eutectic, microstructure transitions

\section{Introduction}

The application of rapid solidification processes offers a broad range of opportunities to produce microstructures that are quite different from those observed in conventionally processed alloys.

For $\mathrm{Pb}-\mathrm{Sn}$ eutectic alloys, Castro et al. observed experimentally anomalous eutectic microstructure with small undercooling levels from 6 to $23 \mathrm{~K}$ using fluxing technique. ${ }^{1)}$ Chu et al. observed, ${ }^{2)}$ in $\mathrm{Pb}-\mathrm{Sn}$ alloys of 29 mass $\% \mathrm{~Pb}$ to 45 mass $\% \mathrm{~Pb}$, the two phase microstructures consisting of tinrich and lead-rich phase when the droplets were highly undercooled. For $\mathrm{Pb}-61.9$ mass $\% \mathrm{Sn}$ alloys, Hua et al. observed the transition from eutectic to primary $\alpha-\mathrm{Pb}$ dendrite plus eutectic when the undercooling was $20 \mathrm{~K}^{3)}$

In the present work, for $\mathrm{Pb}-\mathrm{Sn}$ eutectic alloy, various microstructure transitions were observed with different undercooling levels. Droplets of $\mathrm{Pb}-\mathrm{Sn}$ eutectic alloy were undercooled up to $70 \mathrm{~K}$ by the application of the droplets emulsion technique (DET). ${ }^{4}$ The effectiveness of the droplets emulsion technique for achieving high undercooling depends mostly on the film surrounding each droplet and on the size of the droplets, which in turn depends on the rotating speed. $^{4)}$

The aims of this work are quantitatively to arrange various microstructures of $\mathrm{Pb}-\mathrm{Sn}$ eutectic alloy as a function of the undercooling levels obtained and to rationalize these microstructure transitions on the basis of the Lipton-Kurz-Trivedy theory for dendrite growth and the Jackson-Hunt theory for lamellar eutectic growth. ${ }^{5,6)}$

\section{Experimental}

The alloy was prepared using pure $\mathrm{Pb}$ (granular type, 99.99\%) and Sn (granular type, 99.999\%) by induction melting under vacuum environment.

$\mathrm{Pb}-\mathrm{Sn}$ eutectic alloy powders were made in the oil bath by droplets emulsion technique (DET). DET involves the emulsification of a mixture of liquid metal and a carrier

*Graduate Student, Korea University fluid with a high-speed shearing device under an inert gas environment. By dispersing a liquid metal into fine particles, the nucleation catalysts are trapped within a small fraction of the particles. The majorities of the droplets are free from impurities and can be highly undercooled. ${ }^{4}$ It is possible to reproduce the undercoolings of the droplets emulsified by DET without any change of experimental conditions. Therefore, it is possible to detect precisely the original undercoolings of the droplets by DSC and possible to relate the undercoolings with the microstructures of the droplets.

Figure 1 shows a schematic diagram of the DET apparatus used. A mixture of the $\mathrm{Pb}-\mathrm{Sn}$ eutectic alloy and the oil was placed in a pyrex tube and heated to about $60 \mathrm{~K}$ above the eutecitic temperature of the $\mathrm{Pb}-\mathrm{Sn}$ alloy $\left(T_{\mathrm{e}}=456 \mathrm{~K}\right)$. Then it was sheared at $6000 \sim 18000 \mathrm{rpm}$ to produce an emulsion.

The melting and crystallization behaviors of powders were monitored by a differential scanning calorimeter (DSC, Sinku-Riko, Japan). The emulsion was transferred to sealed aluminum pans and placed within the DSC. Then it was heated at rates of $10 \mathrm{~K}$ per minute and cooled at rates of $2 \mathrm{~K}$ per minute.

For microstructure studies, the emulsion was cleaned ultrasonically in acetone to remove the oil. Then the droplets were mounted and polished for examination using optical microscope (OPTIPHOT-100, Nikon) and a scanning electron microscope (JSM-5310LV, JEOL).

\section{Results}

Undercooling achieved depended to a considerable extent on the type of carrier fluids and the droplet size distribution. ${ }^{4)}$ For example, increasing rotating speed decreased the size of the droplets and the undercooling level obtained was increased. Thus, by changing rotating speed and/or carrier fluid type, various droplets having undercoolings ranging up to $70 \mathrm{~K}$ were obtained intentionally. Figure 2 shows typical DSC thermograms for $\mathrm{Pb}-\mathrm{Sn}$ eutecitic powders. The undercooling is $T_{\mathrm{e}}-T_{\mathrm{s}}$, where $T_{\mathrm{e}}$ is the eutectic temperature and $T_{\mathrm{s}}$ is the onset temperature of solidification.

Figure 3 shows the cross-sectional microstructures of droplets with different undercooling levels. If the droplets 


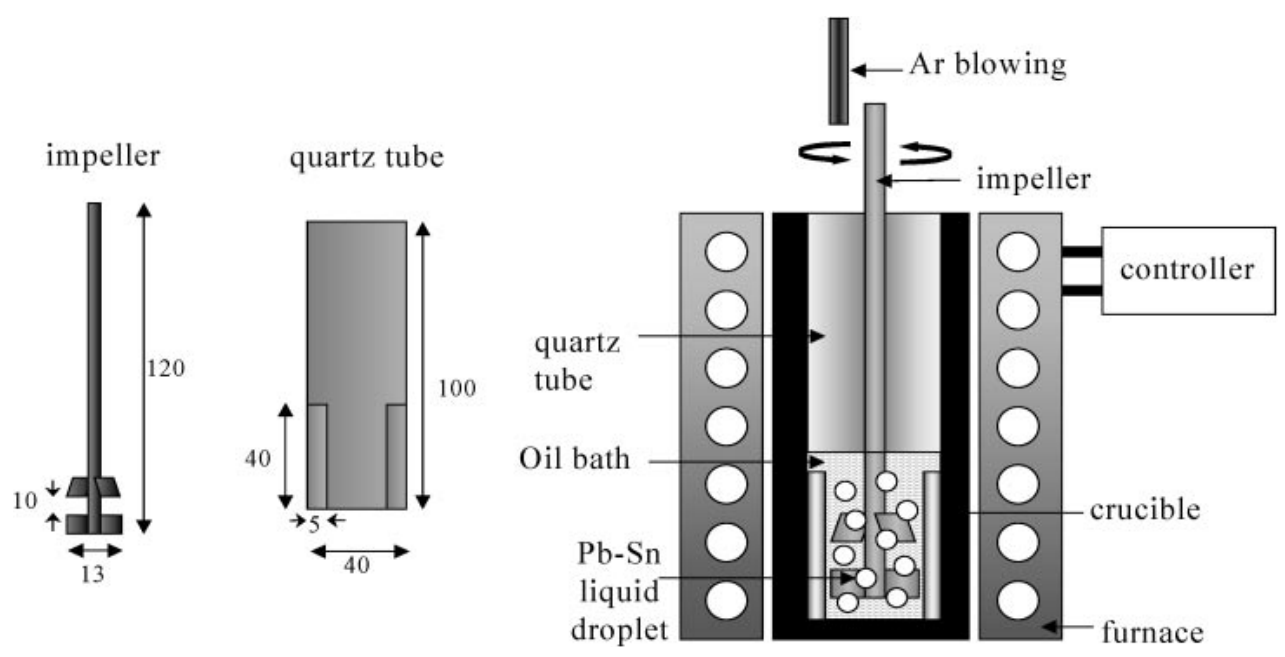

Fig. 1 The apparatus of droplet emulsion technique.

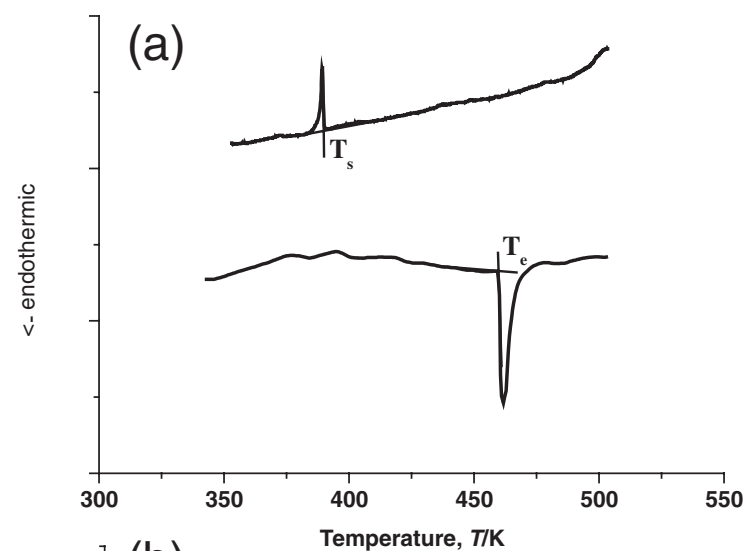

(b)

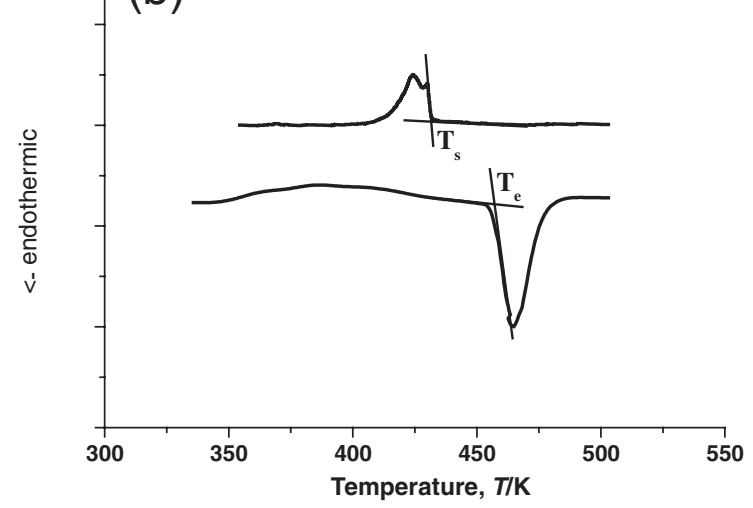

Fig. 2 Typical DSC thermograms of Pb-Sn alloy powders. (a) $\Delta T=70 \mathrm{~K}$, (b) $\Delta T=25 \mathrm{~K}$.

solidify near equilibrium conditions, the microstructure should be a typical lamella eutectic but with increasing undercooling, very different microstructures appeared. Figure 3(a) is the typical lamellar eutectic microstructure of bulk specimen. Figure 3(b) is the primary $\alpha-\mathrm{Pb}$ dendrite plus lamellar eutectic when undercooling is about $25 \mathrm{~K}$. Figures 3 (c) and (d) are the primary $\alpha$-Pb dendrite plus anomalous eutectic when undercooling is about $35 \mathrm{~K}$. Figures 3(e) and (f) show the various morphology of $\alpha-\mathrm{Pb}$ phases when undercooling is in a range of 50 to $70 \mathrm{~K}$.



Fig. 3 The effect of an undercooling on $\mathrm{Pb}$-Sn eutectic microstructure. (a) Bulk, (b) $\Delta T=25 \mathrm{~K}$, (c) $\Delta T=35 \mathrm{~K}$, (d) $\Delta T=35 \mathrm{~K}$ (matrix), (e) $\Delta T=55 \mathrm{~K}$, (f) $\Delta T=70 \mathrm{~K}$.

\section{Discussion}

For an analysis of the growth velocity of each phase at different undercoolings, the LKT dendrite growth and the JH eutectic growth model were referred to.

The LKT dendrite growth theory determines - the undercooling, $\Delta T$-dendrite growth velocity, $V$-dendrite tip radius, $R$ relationship — , according to the following coupled equations. ${ }^{5 \text { ) }}$

$$
\Delta T_{\mathrm{t}}=I_{\mathrm{v}}\left(P_{\mathrm{t}}\right)+C_{0}(A-1)+2 \sigma^{*} P_{\mathrm{t}} F(A)
$$

where $I_{\mathrm{v}}(P)=P \exp (P) E_{1}(P)$ is Ivantsov function in which 
$E_{1}(P)$ is the exponential integral function. $P_{\mathrm{t}}$ is thermal Peclet number.

$$
\begin{aligned}
R & =\left[\sigma^{*} P_{\mathrm{t}} F(A)\right]^{-1} \\
\text { Where } \quad F(A) & =\xi_{\mathrm{t}}+\xi_{\mathrm{c}} 2 \eta C_{0} A(1-k), \\
V & =\sigma^{*} P_{\mathrm{t}}^{2} F(A)
\end{aligned}
$$

where $\eta=a / D$ is the diffusivity ratio. $A$ is the thermal diffusivity and $D$ is the inter-diffusion coefficient. $\xi_{\mathrm{t}}$ and $\xi_{\mathrm{c}}$ are stability parameters. For large Peclet numbers, i.e. large undercoolings, the stability parameters become functions of Peclet numbers. The parameter A represents the concentration ratio, $C_{1}{ }^{*} / C_{0}$, where $C_{1}{ }^{*}$ is the solute concentration in liquid at the tip and $C_{0}$ is the initial alloy composition. The parameter $F(A)$ is equal to $\xi_{\mathrm{t}}-\xi_{\mathrm{c}}\left(G_{\mathrm{c}} / G\right)$ and also equal to the ratio of the stability constant of the alloy to that of the pure substance, $\sigma^{*}\left(C_{0}\right) / \sigma^{*}(0) . G_{\mathrm{c}}$ and $G$ are the concentration gradient and temperature gradient, respectively.

The JH eutectic growth theory determines - the undercooling, $\Delta T$-eutectic growth velocity, $V$-lamellar spacing, $\lambda$ - , relationship according to the following coupled equations. ${ }^{6)}$

$$
\begin{aligned}
\lambda^{2} V & =K_{\mathrm{c}} / K_{\mathrm{r}} \\
\Delta T / V^{1 / 2} & =2\left(K_{\mathrm{c}} K_{\mathrm{r}}\right)^{1 / 2} \\
\Delta T \lambda & =2 K_{\mathrm{r}}
\end{aligned}
$$

where $K_{\mathrm{r}}, K_{\mathrm{c}}$ is constant.

The results of the calculations on the growth velocity of each phase at different undercoolings are represented in Fig. 4. The physical properties of lead-tin eutectic alloy used for the calculation of the growth velocities were obtained from the literature. ${ }^{7-9)}$ The theoretically calculated results were compared with the experimentally observed results in Fig. 5. Based upon the competitive growth principle, i.e. the principle that the most preferred microstructure is that possessing the highest growth velocity at a given undercooling, the microstructure transitions can be predicted. Based on the theoretical calculations, the amount of the critical undercooling was estimated by $55 \mathrm{~K}$. That is, below the amount of the critical undercooling, $\Delta T^{*}=55 \mathrm{~K}$, the growth velocity of the lamellar eutectic phase is higher than that of the $\alpha-\mathrm{Pb}$ phase and the most preferred microstructure is lamellar eutectic microstructure. Thus the typical lamellar eutectic microstructure was observed in the bulk specimen. When the undercooling is about $25 \mathrm{~K}$, the microstructure transition from eutectic to primary $\alpha-\mathrm{Pb}$ dendrite plus eutectic is observed experimentally. Application of LKT and $\mathrm{JH}$ model would predict the critical undercooling for phase transition from eutectic to $\alpha-\mathrm{Pb}$ dendrite plus eutectic that is much larger than that observed experimentally. The discrepancy between the calculated critical undercooling and the experimentally observed critical undercooling results from the assumptions of the model developed by Jackson and Hunt. ${ }^{6)}$ The solution of Jackson and Hunt's model is valid only for low Peclet number and low interface undercooling. In order to assess the conditions under which their model is valid, some of the assumptions were made in their treatment. That is (1) The diffusion distance ahead of the interface, $D / V$, was assumed to be large compared to the eutectic

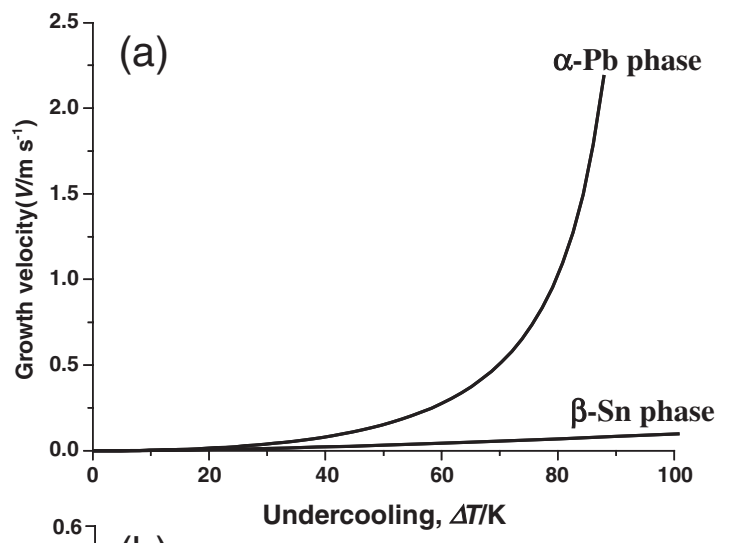

(b)

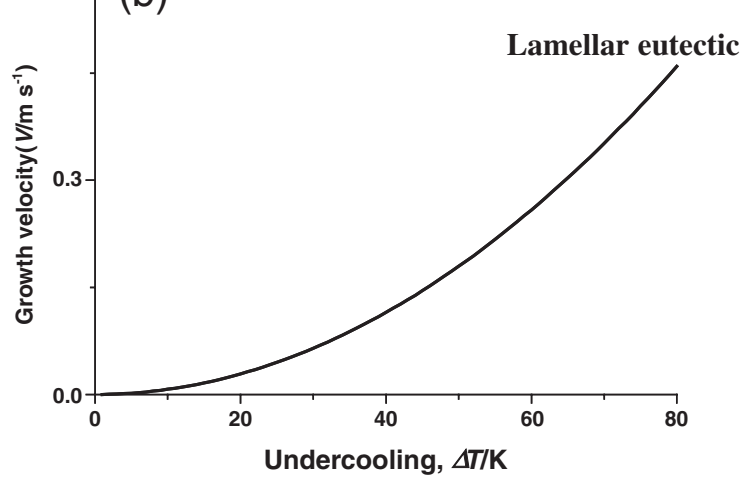

Fig. 4 The theoretically calculated crystal growth velocities in undercooled $\mathrm{Pb}$-Sn eutectic alloy. (a) The growth velocities of dendritic phases. (b) The growth velocity of lamellar eutectic phase.

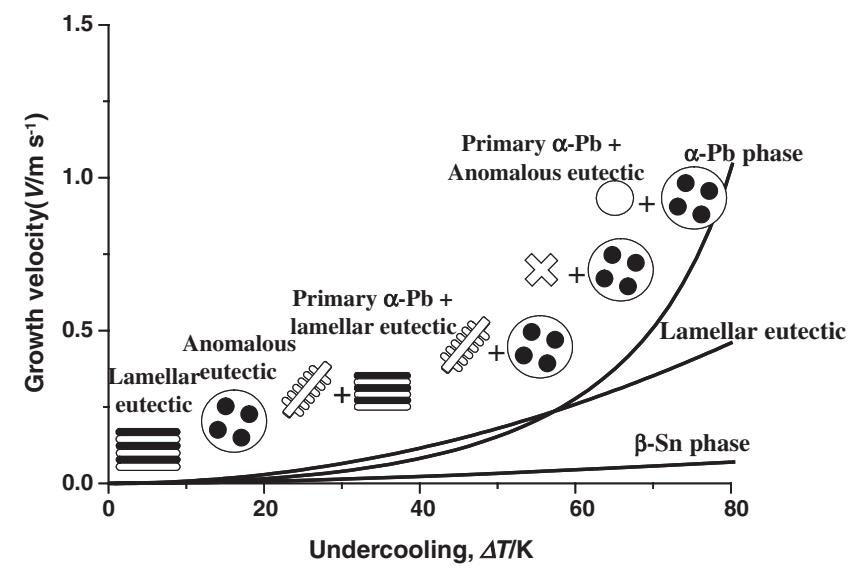

Fig. 5 Crystal growth velocities in undercooled $\mathrm{Pb}-\mathrm{Sn}$ eutectic alloy and the experimentally observed microstructures of $\mathrm{Pb}-\mathrm{Sn}$ eutectic powders.

spacing, $\lambda$, (2) The average curvature of the lamella or the rod was considered only for determining the average capillary undercooling at the interface, (3) The undercooling was considered to be small so that the compositions of $\alpha$ and $\beta$ phases at the interface were independent of undercooling, and (4) The average interface undercooling for the two phases were assumed to be equal. Under higher undercooling levels, however, two new effects become important in influencing the formation and stability of microstructures. That is (1) The effect of high velocity causes the thermal and/ or solutal fields to become more localized, which alters the condition for the diffusive instability of the interface, and (2) 
non-equilibrium effects at the interface become significant which strongly influence the phase and microstructure selection criteria. Because the assumptions for Jackson and Hunt's model were not valid any longer for higher undercooling levels, the discrepancy between experimental findings and theoretically calculated results was occurred.

In the slightly larger undercooling levels than $0 \mathrm{~K}$, the growth velocity of the $\alpha-\mathrm{Pb}$ phase can be orders of magnitude larger than that of $\beta$-phase. Thus the coupled growth conditions are destroyed at this undercooling range ${ }^{10)}$ resulting in a transition from lamellar eutectic growth to anomalous eutectic growth. Castro et al. observed experimentally the transition from lamellar eutectic to anomalous eutectic with critical undercooling, $\Delta T^{*}=6 \mathrm{~K} .{ }^{1)}$ Because the undercooling level, $\Delta T^{*}=6 \mathrm{~K}$, is too small to obtain using DET, the transition from lamellar eutectic to anomalous eutectic in the low undercooling levels was not observed experimentally. Instead, at the higher undercooling level, $\Delta T=35 \mathrm{~K}$, the transition from lamellar eutectic with primary the $\alpha-\mathrm{Pb}$ dendrites to anomalous eutectic with the primary $\alpha-\mathrm{Pb}$ dendrites could be observed experimentally. At the undercooling levels above $35 \mathrm{~K}$, morphological transitions from dendrites to equiaxed grains of primary $\alpha-\mathrm{Pb}$ phases with anomalous eutectic were also observed experimentally. It is well known that the rapid crystal nucleation, growth, and the marked solute trapping effect under high undercooling conditions are responsible for these morphological transitions. ${ }^{11)}$

\section{Conclusions}

Various microstructures of $\mathrm{Pb}-\mathrm{Sn}$ eutectic alloy obtained depend strongly on undercoolings and were quantitatively arranged as a function of the undercooling levels. When the undercooling is above $25 \mathrm{~K}$, the microstructure transition from eutectic to primary $\alpha-\mathrm{Pb}$ dendrite plus eutectic is observed. The reason for this transition may be that the growth velocity of the $\alpha-\mathrm{Pb}$ phase exceeds that of the lamellar eutectic phase at large undercooling. When the undercooling is about $35 \mathrm{~K}$, anomalous eutectic with primary $\alpha-\mathrm{Pb}$ dendrites appeared instead of the usual lamellar eutectic with primary $\alpha-\mathrm{Pb}$ dendrites. In previous literature, the transition from lamellar to anomalous eutectic was observed at the low undercooling levels, $6 \mathrm{~K}$. Because these low undercooling levels couldn't be obtained using DET process, the transition from lamellar to anomalous eutectic at the low undercooling levels was not observed. By the theoretically calculated result, however, the reason for this transition may be that the growth velocity of the $\alpha$-Pb phase can be orders of magnitude larger than that of $\beta$-Sn phase at the slightly larger undercooling levels than $0 \mathrm{~K}$, consequently destroys the coupled growth conditions required for lamellar eutectic growth. At the undercooling levels above $35 \mathrm{~K}$, morphological transitions from dendrites to equiaxed grains of primary $\alpha$ - $\mathrm{Pb}$ phases with anomalous eutectic were also observed experimentally.

\section{Acknowledgements}

This research was performed by the financial support of 'Center for Nanostructured Materials Technology' under '21st Century Frontier R\&D Programs' of the Ministry of Science and Technology, Korea. This research was also supported by Korea University Grant in 2003 year.

\section{REFERENCES}

1) W. B. de Castro, M. de Lucena Maia, C. S. Kiminami and C. Bolfarini: Mater. Sci. Eng. A304-306 (2001) 255-261.

2) M. G. Chu, Y. Shiohara and M. C. Flemings: Metall. Trans. A 15A (1984) 1303-1310.

3) F. Hua and R. N. Grugel: Metall. Mater. Trans. A 26A (1995) 26992706.

4) J. H. Perepezko: Mater. Sci. Eng. 65 (1984) 125-135.

5) J. Lipton, W. Kurz and R. Trivedi: Acta Mater. 35 (1987) 957-964.

6) K. A. Jackson and J. D. Hunt: Trans. Metall. Soc. AIME 236 (1966) 1129-1142.

7) E. Cadirli and M. Gunduz: J. Mater. Process. Technol. 97 (2000) 74-81.

8) Joseph. R. Davis and Penelope Allen: Metals Handbook, vol. 2, 10th ed. (ASM international, U.S.A, 1990) pp. 1099-1100.

9) D. R. Lide: CRC Handbook of Chemistry and Physics, 71st ed. (CRC Press, U.S.A, 1990-1991) pp. 5.64-5.67.

10) B. Wei, D. M. Herlach, F. Sommer and W. Kurz: Mater. Sci. Eng. A181/A182 (1994) 1150-1155.

11) X. J. Han, C. Yang, B. Wei, M. Chen and Z. Y. Guo: Mater. Sci. Eng. A307 (2001) 35-41. 